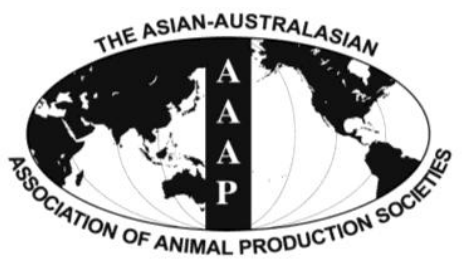

Asian-Aust. J. Anim. Sci.

Vol. 26, No. 2 : 171-177 February 2013

http://dx.doi.org/10.5713/ajas.2012.12478

www.ajas.info

pISSN 101 1-2367 elSSN 1976-5517

\title{
Post-parturient Disorders and Backfat Loss in Tropical Sows in Relation to Backfat Thickness before Farrowing and Postpartum Intravenous Supportive Treatment
}

\author{
Padet Tummaruk* \\ Department of Obstetrics, Gynaecology and Reproduction, Faculty of Veterinary Science, \\ Chulalongkorn University, Bangkok, 10330, Thailand
}

\begin{abstract}
The aim of the present study was to determine the evidence of post-parturient disorders and backfat loss during lactation in sows raised in tropical areas in relation to their backfat thickness before farrowing and postpartum intravenous supportive treatment. Backfat thickness was measured using A-mode ultrasonography at farrowing and weaning $(25.5 \pm 1.4 \mathrm{~d})$ in 70 sows. The sows were divided into three groups according to backfat thickness before farrowing, i.e., 15.0 to $20.0 \mathrm{~mm}(\mathrm{n}=21), 20.5$ to $25.0 \mathrm{~mm}(\mathrm{n}=35)$, $>25.0 \mathrm{~mm}(\mathrm{n}=14)$ and were categorized into two groups according to the postpartum supportive treatment, i.e., control $(\mathrm{n}=31)$ and treatment $(n=39)$. After farrowing, the sows in treatment group received the same medications as in control sows. Furthermore an intravenous supportive treatment with amino acids and vitamins was administered in treatment groups. Rectal temperature and clinical signs of the sows including vaginal discharge, udder problems and appetite were determined at d 0, 1, 2 and 3 of parturition. It was found that, on average, the backfat thickness was $22.4 \pm 3.9 \mathrm{~mm}$ at farrowing and $19.9 \pm 2.9 \mathrm{~mm}$ at weaning. The backfat loss and the relative backfat loss during the lactation period were $2.6 \mathrm{~mm}$ and $10.6 \%$, respectively. The sows with a backfat of 15.0 to $20.0 \mathrm{~mm}$ before farrowing lost less backfat than those with a backfat of 20.5 to $25.0 \mathrm{~mm}$ and $>25.0 \mathrm{~mm}(\mathrm{p}<0.05)$. Sows with a backfat of 15.0 to $20.0 \mathrm{~mm}$ had a better appetite on $\mathrm{d} 1$ postpartum than sows with a backfat of 20.5 to $25.0 \mathrm{~mm}(\mathrm{p}=0.020)$. The percentage of sows losing backfat $>10 \%$ during lactation were higher in sows with a backfat of $>25.0 \mathrm{~mm}$ before farrowing $(85.7 \%)$ than sows with a backfat of 15.0 to $20.0 \mathrm{~mm}$ before farrowing $(35.0 \%)(\mathrm{p}=0.008)$. The percentage of sows with a reduced appetite on $\mathrm{d} 1(90.3 \% \mathrm{vs} 71.8 \%, \mathrm{p}=$ $0.018)$ and $\mathrm{d} 2(61.3 \%$ versus $33.3 \%, \mathrm{p}=0.005)$ postpartum in the treatment group was lower than the control group. In conclusion, the backfat thickness of sows at farrowing influenced backfat loss during lactation under hot and humid climates. The intravenous supportive treatment of sows with amino acid and vitamins significantly improved the appetite of postpartum sows. (Key Words: Pig, Reproduction, Parturition, Backfat, Mastitis)
\end{abstract}

\section{INTRODUCTION}

Post-parturient disorders in sows often lead to sow's lactation problems and the high pre-weaning mortality of their offspring. Piglet pre-weaning mortality mainly occurs during the first four days of life and the most critical period is the first $24 \mathrm{~h}$ after birth (Marchant et al., 2000). In most cases, the death of the piglets during the early period of life is caused by inadequate colostrum intake, starvation and hypothermia. Inadequate colostrum intake relates to inadequate transfer of maternal immunity and body weight gain of the piglets during lactation period (Milligan et al.,

\footnotetext{
* Corresponding Author: Padet Tummaruk. Tel: +66-2-2189651, Fax: +66-2-2520738, E-mail: Padet.T@chula.ac.th Submitted Sept. 6, 2012; Accepted Oct. 16, 2012; Revised Oct. 29, 2012
}

2002; Markowska-Daniel and Pomorska-Mol, 2010). During recent years, the terminology "postpartum dysgalactia syndrome (PDS)" in sows has been defined and being intensively investigated (Klopfenstein et al., 2006; Kemper and Gerjets, 2009; Papadopoulos et al., 2010). PDS is defined as symptoms involving insufficient colostrum and milk production during the first day after farrowing. Also, it includes postpartum metritis, mastitis and agalactia syndrome (MMA) (Klopfenstein et al., 2006). Factors that have been reported to increase the incidence of PDS include the very short period of transferring the gestating sows to the farrowing pen, the parturition induction, the time of introducing feed up to ad libitum postpartum and the feeding during late gestation (Papadopoulos et al., 2010). To minimize the incidence of the postparturient disorders in sows, data concerning the management and supportive 
treatment around parturition needs to be investigated.

In Thailand, most of the lactating sows are housed in open-housing systems and heat stress is commonly seen. The outdoor temperature and relative humidity have a large impact on pig production in Thailand (Suriyasomboon et al., 2006; Tummaruk, 2010). Common features of the tropical climate's effect on the sows' reproductive performance include a decreased conception rate, an increased embryonic loss and a prolonged weaning-to-first-service interval (Love et al., 1993; Peltoniemi et al., 1999; Tummaruk et al., 2000; Tummaruk et al., 2004). The inferior reproductive performance of the sows in tropical climates is largely dependent on body weight and/or backfat loss during the lactation period (Tantasuparuk et al., 2001; Tummaruk et al., 2010) as well as postpartum illnesses. It has been suggested that a greater weight loss of the sows during the lactation period relates to a greater feed intake and weight gain during pregnancy (Einarsson and Rojkittikhun, 1993). Because of heat stress, sows kept in tropical climates tend to have a relatively poor feed intake during lactation and have a high risk of fat and/or body weight loss. Thus, the backfat thickness of sows before farrowing should be carefully determined. The aim of the present study was to determine the evidence of postparturient disorders and backfat loss in sows during lactation in Thailand in relation to their backfat thickness before farrowing and postpartum intravenous supportive treatment.

\section{MATERIAL AND METHODS}

\section{Animals}

The study was conducted between May and August 2011 in a commercial swine herd in the eastern region of Thailand. In total, 70 Landrace $\times$ Yorkshire crossbred sows were included (mean parity number $1.8 \pm 1.3$ ). The sows were classified according to parity number into parity $1(\mathrm{n}=$ $37), 2(n=23)$ and 3 to $8(n=10)$. The gilts and sows were housed in an open-housing system with equipment to reduce the impact of high ambient temperatures. During the study period, the average outdoor daily (24-h) minimum and maximum temperatures and the average relative humidity were $25.0 \pm 0.8^{\circ} \mathrm{C}, 34.1 \pm 1.9^{\circ} \mathrm{C}$ and $83.5 \pm 5.1 \%$, respectively. The gilts and sows entered the farrowing house approximately one week before the expected farrowing date. They were kept in pens with a space allowance of 4.5 $\mathrm{m}^{2} /$ sow. Gilts/sows were vaccinated against foot-and-mouth disease before farrowing and classical swine fever and porcine parvovirus after farrowing. Vaccination for Aujeszky's disease was performed in all gilts and sows every four months. During lactation, the gilts and sows were fed twice a day (about 5 to $6 \mathrm{~kg}$ of feed/d) with a ricecorn-soybean-chicken ration containing $18.0 \%$ crude protein, 3,250 kcal/kg metabolisable energy and $1.10 \%$ lysine. Each 1,000 kg of the feed contained corn (400 kg), cassava $(100 \mathrm{~kg})$, rice bran $(170 \mathrm{~kg})$, soybean $(240 \mathrm{~kg})$, chicken (40 kg), calcium/phosphorus (14 kg), salt (4 kg), rice bran oil $(30 \mathrm{~kg})$, methionine $(0.3 \mathrm{~kg})$ and other vitamins/mineral premixes $(2.7 \mathrm{~kg})$. The gilts were bred at $>32$ wks of age, at the second or later estrus and at a body weight of $>130 \mathrm{~kg}$. All insemination in the herds was carried out using a conventional artificial insemination (AI). At farrowing, the date of farrowing, the total number of piglets born/litter (TB), the number of piglet born alive per litter (BA), the percentage of stillborn piglets per litter and the percentage of mummified fetuses per litter were recorded. The duration of parturition of individual sow was also recorded. The duration of parturition was defined as the period from the first to the last piglets delivery. After weaning, the weaning-to-first service interval was also recorded.

\section{Measurements of backfat thickness}

Backfat thickness was measured using A-mode ultrasonography (Renco Lean-Meater ${ }^{\circledR}$, Minneapolis, MN, USA) before farrowing and at weaning $(25.5 \pm 1.4 \mathrm{~d})$. Backfat thickness was measured at the level of the last rib at about 6 to $8 \mathrm{~cm}$ from the midline, on both sides of the sows (Tummaruk et al., 2007). An average between the left and the right sides was calculated. Backfat loss in each sow was defined as the difference between backfat thickness at farrowing and at weaning. Relative backfat loss of each sow was defined as the backfat loss ( $\mathrm{mm}$ ) divided by backfat at farrowing and multiplied by 100 . The relative loss of backfat was expressed as a percentage.

\section{Classification of sows}

According to the backfat thickness before farrowing, the sows were divided into three groups, i.e., 15.0 to $20.0 \mathrm{~mm}$ $(\mathrm{n}=21), 20.5$ to $25.0 \mathrm{~mm}(\mathrm{n}=35)$ and $>25.0 \mathrm{~mm}(\mathrm{n}=14)$. Due to the postpartum medication, the sows were divided into two groups, i.e., control $(n=31)$ and treatment $(n=39)$. The control sows received antibiotics (Amoxycillin Clavulanic acid, Synulox ${ }^{\circledR}$, Pfizer, USA), anti-inflammatory drug (Tolfédine ${ }^{\circledR}$, Vétoquinol, France) and vitamins (Fercobseang ${ }^{\circledR}$, Vétoquinol, France) after farrowing without intravenous supportive treatment with amino acids and vitamin compounds. The treated sows received the same treatment as the control sows with the addition of intravenous administration of amino acids and vitamin compounds $50 \mathrm{ml} / \mathrm{sow}\left(0.25 \mathrm{ml} / \mathrm{kg}\right.$ Amino-Lite ${ }^{\circledR} 34 \mathrm{X}$, Dispar International Laboratories Ltd., Quebec, Canada). The amino acids and vitamin compounds contain a cluster of amino acids (i.e., $D L$-tryptophan, $L$-arginine, $L$-cysteine, $D L$-phenylalanine, $L$-lysine, $L$-histidine, $L$-methionine, $D L$ valine, $L$-threonine, $L$-glutamine, $D L$-isoleucine and $L$ - 
leucine), vitamins (i.e., B1, B2, B12 and nicotinamide) and other ingredients (e.g., calcium, dextrose, magnesium, potassium, citric acid, etc.). The sows were also categorized according to the duration of parturition, i.e., $\leq 2 \mathrm{~h}(\mathrm{n}=37)$ and $>2 \mathrm{~h}(\mathrm{n}=29)$.

\section{Post-parturient disorders}

The rectal temperature and the clinical signs of the postpartum sows including the presence of abnormal vaginal discharge, PDS, reduced appetite were determined at $\mathrm{d} 0,1,2$ and 3 of parturition. Sows with a rectal temperature $\geq 39.5^{\circ} \mathrm{C}$ were regarded as fever. Fever is a binomial trait defined as ' 0 ' when the sows had no fever and ' 1 ' when the sows had a fever. Abnormal vaginal discharge was defined according to the presence or absence of postpartum abnormal vaginal discharge (i.e., exudates or bloody discharge of dark grey to white). Abnormal vaginal discharge was defined as ' 1 ' when a certain amount of abnormal discharge $(\geq 5 \mathrm{ml})$ was observed and ' 0 ' if abnormal discharge was absent or only a small amount of transudate (lochia) was seen. PDS was defined according to the presence or absence of the udder inflammation and/or agalactia. Inflammation is the reddening and swelling of the udders. If at least one udder had inflammation or agalactia, PDS was defined as ' 1 ' otherwise it was defined as ' 0 '. Reduced appetite was defined as ' 0 ' if the sows had a good appetite ( $>80 \%$ of the daily feed provided eaten) and defined as ' 1 ' if the sows showed signs of reduced appetite (e.g., diminished feed intake to total anorexia (no feed eaten at all)) (Glock and Bilkei, 2005). All parameters were determined in each sow at d 0, 1,2 and 3 postpartum.

\section{Statistical analysis}

Statistical analyses were performed using SAS (SAS, 2002). Descriptive statistics (means, standard deviations (SD) and ranges) and frequency tables were employed for all reproductive parameters. Multiple analysis of variance (ANOVA) was conducted to analyze continuous dependent variables including backfat at farrowing and at weaning, backfat loss, relative backfat loss and duration of parturition by using general linear model (GLM) procedure of SAS. The statistical models included the effect of parity number (1, 2 and $\geq 3)$, backfat at farrowing (15.0 to 20.0, 20.5 to 25.0 and $>25.0 \mathrm{~mm}$ ), duration of parturition ( $\leq 2$ and $>2 \mathrm{~h}$ ) and the type of postpartum medication (control and treatment). Two way interactions among those factors were tested for significance but were omitted from the model due to insignificance. Least-squares means were obtained from each class of the factors and were compared using the least significant different test. Binomial traits including backfat loss class $(\leq 10 \%$ and $>10 \%)$, fever $(0,1)$, vaginal discharge $(0,1)$, PDS $(0,1)$ and reduced appetite $(0,1)$ at $\mathrm{d} 0,1,2$ and 3 after parturition were analyzed using logistic regression under PROC GENMOD of SAS. The statistical models included the effect of parity number $(1,2$ and $\geq 3)$, backfat at farrowing (15.0 to $20.0,20.5$ to 25.0 and $>25.0 \mathrm{~mm}$ ), duration of parturition ( $\leq 2$ and $>2 \mathrm{~h}$ ) and the type of postpartum medication (control and treatment). Pairwise comparisons were conducted in each class of the factors and were compared using least significant difference test. $\mathrm{p}<0.05$ was considered statistically significant.

\section{RESULTS}

\section{Duration of parturition}

Descriptive data on reproductive performance of postpartum sows are presented in Table 1. On average, the duration of parturition was $117.2 \pm 47.3 \mathrm{~min}$ (range 28 to 383 min). The duration of parturition did not differ significantly among sows with a different backfat at farrowing (Table 2). On average, the sows with a short duration of parturition $(\leq 2 \mathrm{~h})$ spent $85.2 \pm 7.8 \mathrm{~min}$ to complete the farrowing process, while those with a long duration of parturition $(>2$ h) spent $145.8 \pm 8.2$ min completing farrowing process. TB tended to be higher in sows with a long duration of parturition than those with a short duration of parturition (11.5 vs 12.7 piglets/litter, $p=0.066$ ). The duration of parturition did not differ significantly between sows treated with conventional medication and those treated with an intravenous amino acid compound supplementation (Table 3).

\section{Backfat thickness and backfat loss}

Of all the sows $(n=70)$, backfat thickness was not determined at weaning in 4 sows, therefore only 66 sows were included in the analysis of backfat loss. On average, the backfat before farrowing was $22.4 \pm 3.9 \mathrm{~mm}$ (range 15.0 to 33.0) and the backfat at weaning was $19.9 \pm 2.9 \mathrm{~mm}$ (range 14.0 to 26.5). The mean backfat loss and the relative backfat loss of the sows during lactation period were 2.6 $\mathrm{mm}$ and $10.6 \%$, respectively. Of these sows $(\mathrm{n}=66), 7$

Table 1. Descriptive statistics

\begin{tabular}{lcc}
\hline Parameters & Mean \pm SD & Range \\
\hline Farrowing duration (min) & $117.2 \pm 47.3$ & $28-383$ \\
Total number of piglets born/L & $12.1 \pm 2.5$ & $5-17$ \\
Number of piglets born alive/L & $11.4 \pm 2.4$ & $5-17$ \\
Mummified fetuses/L (\%) & 1.7 & $0-15.3$ \\
Stillborn piglets/L (\%) & 3.8 & $0-23.1$ \\
Backfat at farrowing (mm) & $22.4 \pm 3.9$ & $15.0-33.0$ \\
Backfat at weaning (mm) & $19.9 \pm 2.9$ & $14.0-26.5$ \\
Backfat loss (mm) & $-2.6 \pm 2.2$ & $-8-+3$ \\
Relative backfat loss (\%) & $-10.9 \pm 8.5$ & $-28.1-+12.9$ \\
Lactation (d) & $25.5 \pm 1.5$ & $22-32$ \\
Weaning-to-service interval (d) & $5.2 \pm 2.1$ & $4-16$ \\
\hline
\end{tabular}


Table 2. Lsmeans \pm SEM of reproductive performance of postpartum sows by backfat thickness at farrowing

\begin{tabular}{|c|c|c|c|}
\hline \multirow{2}{*}{ Items } & \multicolumn{3}{|c|}{ Backfat thickness at farrowing } \\
\hline & 15.0 to 20.0 & 20.5 to 25.0 & $>25.0$ \\
\hline Number of sows & 20 & 30 & 14 \\
\hline Farrowing duration (min) & $104.2 \pm 12.7^{\mathrm{a}}$ & $113.4 \pm 9.9^{\mathrm{a}}$ & $112.4 \pm 12.8^{\mathrm{a}}$ \\
\hline Total number of piglet born/L & $13.0 \pm 0.7^{\mathrm{a}}$ & $11.6 \pm 0.5^{\mathrm{a}}$ & $11.5 \pm 0.7^{\mathrm{a}}$ \\
\hline Number of piglets born alive/L & $12.2 \pm 0.6^{\mathrm{a}}$ & $10.7 \pm 0.5^{\mathrm{b}}$ & $11.0 \pm 0.6^{\mathrm{b}}$ \\
\hline Backfat at farrowing $(\mathrm{mm})$ & $18.6 \pm 0.4^{\mathrm{a}}$ & $22.7 \pm 0.3^{\mathrm{b}}$ & $28.5 \pm 0.4^{\mathrm{c}}$ \\
\hline Backfat at weaning (mm) & $17.4 \pm 0.5^{\mathrm{a}}$ & $20.5 \pm 0.4^{\mathrm{b}}$ & $23.4 \pm 0.5^{\mathrm{c}}$ \\
\hline Backfat loss (mm) & $1.1 \pm 0.5^{\mathrm{a}}$ & $2.3 \pm 0.4^{\mathrm{b}}$ & $5.1 \pm 0.5^{\mathrm{c}}$ \\
\hline Relative backfat loss (\%) & $5.8 \pm 2.1^{\mathrm{a}}$ & $10.3 \pm 1.6^{\mathrm{b}}$ & $17.9 \pm 2.1^{\mathrm{c}}$ \\
\hline Lactation $(\mathrm{d})$ & $25.9 \pm 0.4^{\mathrm{a}}$ & $25.7 \pm 0.3^{\mathrm{a}}$ & $25.4 \pm 0.4^{\mathrm{a}}$ \\
\hline Weaning-to-service interval (d) & $4.9 \pm 0.6^{\mathrm{a}}$ & $4.6 \pm 0.4^{\mathrm{a}}$ & $5.6 \pm 0.6^{\mathrm{a}}$ \\
\hline
\end{tabular}

${ }^{\text {abc }}$ Different superscript within row differed significantly.

sows $(10.6 \%)$ did not lose any backfat during lactation, while 22 sows $(33.3 \%), 31$ sows $(47.9 \%)$ and 6 sows (9.1\%) lost backfat 1 to $10 \%, 11$ to $20 \%$ and 21 to $30 \%$ during lactation. The backfat of sows before farrowing influenced their backfat loss during lactation period ( $\mathrm{p}=$ 0.002). For instance, sows entering the farrowing house with a backfat of 15.0 to $20.0 \mathrm{~mm}$ lost backfat during lactation less than those entering the farrowing house with a backfat of 20.5 to $25.0 \mathrm{~mm}$ and $>25.0 \mathrm{~mm}$ (Table 2). The percentage of sows losing backfat 21 to $30 \%$ during lactation was highest in sows entering the farrowing house with a backfat of $>25.0 \mathrm{~mm}$ (Figure 1). On the other hand, up to $20 \%$ of the sows entering the farrowing house with a backfat of 15.0 to $20.0 \mathrm{~mm}$ did not lose any backfat during lactation and none of them lost more than $20 \%$ backfat during lactation (Figure 1). Postpartum medication did not influence backfat loss during lactation ( $>>0.05$ ) (Table 3 ).

The backfat of sows before farrowing influenced the proportion of sows with a reduced appetite on $\mathrm{d} 1$ postpartum $(\mathrm{p}<0.05)$. Sows with backfat of 15.0 to $20.0 \mathrm{~mm}$ before farrowing had a better appetite on $\mathrm{d} 1$ postpartum than sows with backfat of 20.0 to $25.0 \mathrm{~mm}(\mathrm{p}=0.020)$. The backfat of sows before farrowing did not influence the incidence of fever, vaginal discharge and udder problems during the first three days postpartum ( $\mathrm{p}>0.05)$.

The results revealed that the sows losing backfat $>10 \%$ accounted for $43.9 \%(\mathrm{n}=29)$, and those losing backfat $\leq 10 \%$ accounted for $56.1 \%(\mathrm{n}=37)$. It was also found that the percentage of sows losing backfat $>10 \%$ during lactation was higher in those with a backfat at farrowing of $>25.0 \mathrm{~mm}$ than those with a backfat at farrowing of 15.0 to $20.0 \mathrm{~mm}(\mathrm{p}=0.008)$ (Table 2, Figure 1). Neither the duration of parturition nor postpartum medication influenced the backfat loss during lactation $(\mathrm{p}>0.05)$ (Table 3).

\section{Postpartum supportive treatment}

The percentage of sows with postpartum disorders including fever, reduced appetite, abnormal vaginal discharge and PDS at d 1 and 2 of parturition are presented in Table 4 and Figure 2. The percentage of reduced appetite sows on day $1(90.3 \%$ vs $71.8 \%, p=0.018)$ and $d 2(61.3 \%$ vs $33.3 \%, p=0.005)$ postpartum in the treatment group were lower than in the control group (Table 4). Postpartum supportive treatment did not influence backfat loss and weaning-to-service interval ( $\mathrm{p}>0.05)$.

Across the groups, 50 out of 70 sows $(71.4 \%)$ had fever on $\mathrm{d} 1$ postpartum and 47 out of 70 sows $(67.1 \%)$ still had a

Table 3. Lsmeans \pm SEM of postpartum reproductive performance of control and treatment sows (amino acid supplementation)

\begin{tabular}{lccc}
\hline Parameters & Control & Treatment & p-value \\
\hline Number of sow & \multicolumn{1}{c}{ - } & 39 & \\
Farrowing duration (min) & $110.0 \pm 10.0$ & $109.9 \pm 9.2$ & 0.996 \\
Total number of piglet born/L & $11.6 \pm 0.5$ & $12.4 \pm 0.5$ & 0.198 \\
Number of piglets born alive/L & $10.9 \pm 0.5$ & $11.6 \pm 0.4$ & 0.279 \\
Backfat at farrowing (mm) & $23.7 \pm 0.3$ & $22.9 \pm 0.3$ & 0.047 \\
Backfat at weaning (mm) & $20.7 \pm 0.4$ & $20.2 \pm 0.4$ & 0.286 \\
Backfat loss (mm) & $2.9 \pm 0.4$ & $2.7 \pm 0.3$ & 0.631 \\
Relative backfat loss (\%) & $11.9 \pm 1.6$ & $10.8 \pm 1.5$ & 0.588 \\
Lactation (d) & $25.6 \pm 0.3$ & $25.6 \pm 0.3$ & 0.968 \\
Weaning-to-service interval (d) & $4.6 \pm 0.5$ & $5.6 \pm 0.4$ & 0.095
\end{tabular}




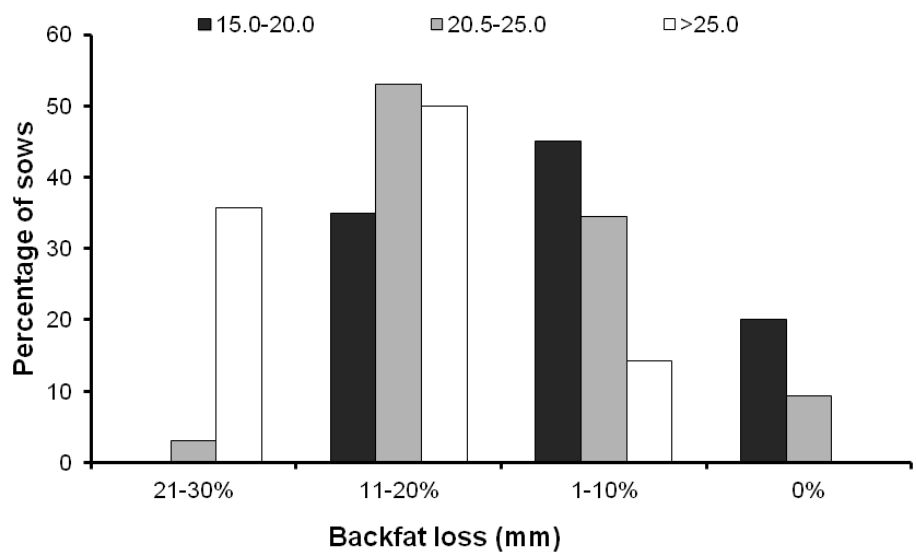

Figure 1. Proportion of weaned sows losing backfat $0 \%, 1$ to $10 \%, 11$ to $20 \%$ and 21 to $30 \%$ by group of backfat thickness at farrowing (15.0 to $20.0,20.5$ to 25.0 and $>25.0 \mathrm{~mm}$ ).

fever on $\mathrm{d} 2$ postpartum. The intravenous supportive treatment did not influence the proportion of sows with fever at $\mathrm{d} 1$ and 2 postpartum ( $\mathrm{p}>0.05)$. Likewise, postpartum supportive treatment did not influence the incidence of udder problems ( $p>0.05)$.

\section{DISCUSSION}

During recent years, researchers have tried to investigate factors affecting the sow's ability to produce adequate milk for their offspring in order to enhance piglet growth and reduce the piglet pre-weaning mortality rate (Markowska-Daniel and Pomorska-Mol, 2010; Kemper and Gerjets, 2009; Papadopoulos et al., 2010). In tropical climates, such studies have never been comprehensively undertaken. In tropical countries, it was well established that the reproductive performance of sows was inferior to the same breed being raised in Europe and North America (Tummaruk et al., 2000; Tummaruk et al., 2010). The reason might be partly due to the fact that lactating sows may not receive enough feed intake during lactation period, especially during the first few days postpartum. In Thailand, most sows are kept in open housing systems and such a hot and humid climate may decrease feed intake and reduce the
Table 4. Percentage of sows with post-parturient disorders on $\mathrm{d} 1$ and 2 postpartum in control and in amino-acid-supplemented sows (treatment)

\begin{tabular}{lccccc}
\hline \multirow{2}{*}{ Parameter } & \multicolumn{2}{c}{ Day 1 } & & \multicolumn{2}{c}{ Day 2 } \\
\cline { 2 - 3 } \cline { 5 - 6 } & Control & Treatment & & Control & Treatment \\
\hline Fever (\%) & $71.0^{\mathrm{a}}$ & $71.8^{\mathrm{a}}$ & & $64.5^{\mathrm{a}}$ & $69.2^{\mathrm{a}}$ \\
Low appetite (\%) & $90.3^{\mathrm{a}}$ & $71.8^{\mathrm{b}}$ & & $61.3^{\mathrm{a}}$ & $33.3^{\mathrm{b}}$ \\
Vulva discharge (\%) & $41.9^{\mathrm{a}}$ & $12.8^{\mathrm{b}}$ & & $61.3^{\mathrm{a}}$ & $30.8^{\mathrm{b}}$ \\
PDS $^{2}(\%)$ & $16.1^{\mathrm{a}}$ & $5.1^{\mathrm{a}}$ & & $32.3^{\mathrm{a}}$ & $20.5^{\mathrm{a}}$ \\
\hline
\end{tabular}

\footnotetext{
${ }^{1}$ Fever $=$ Rectal temperature $\geq 39.5^{\circ} \mathrm{C}$.

${ }^{2}$ Postpartum dysgalactia syndrome.

a,b Different superscript between column within day differed significantly $(\mathrm{p}<0.05)$.
}

appetite of the sows. During the study period, the mean temperature during the daytime was as high as $34.1 \pm 1.9^{\circ} \mathrm{C}$ with a mean relative humidity of $83.5 \pm 5.1 \%$. This might have caused moderate to severe heat stress in some sows. Furthermore, the effect of such an extremely high relative humidity in Thailand on the reproductive performance of sows has also been comprehensively investigated in both gestating (Tummaruk et al., 2004; Tummaruk et al., 2010) and lactating sows (Suriyasomboon et al., 2006). Previous study demonstrated that up to $0.8 \mathrm{~TB}$ was reduced when relative humidity was increased from $50 \%$ to $80 \%$

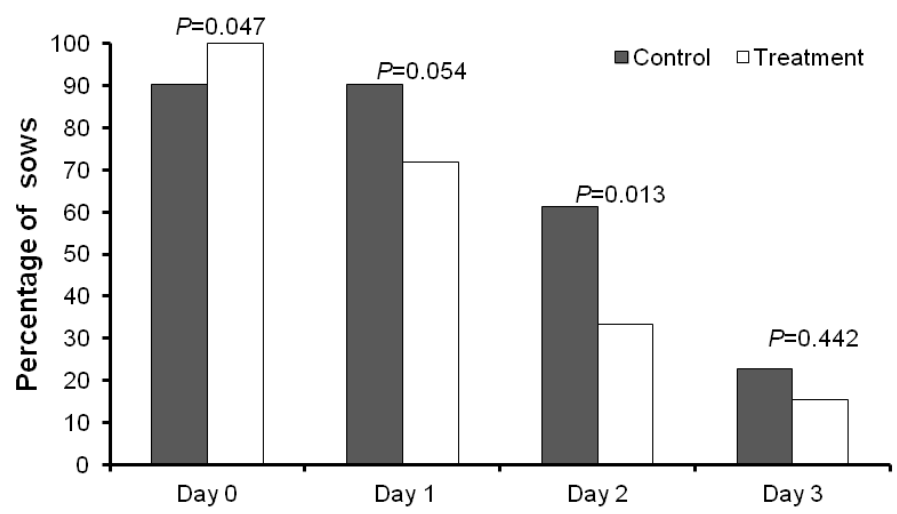

Figure 2. Proportion of postpartum sows with low appetite in control and treatment groups on d 0,1,2 and 3 postpartum. 
(Tummaruk et al., 2010). In the present study, a relatively high proportion of sows with reduced appetite during the first 2 d post-partum was noticed (i.e., up to $90 \%$ at d 1). It was found that intravenous supportive treatment with amino acid and vitamin compounds significantly reduced the proportion of sows with low appetite during the first $2 \mathrm{~d}$ postpartum. Furthermore, sows with a low backfat (i.e., 15.0 to $20.0 \mathrm{~mm}$ ) at farrowing were able to maintain their backfat during lactation better than those with a high backfat at farrowing. This data indicates that, under hot and humid climates, the sows with a fairly low backfat at farrowing (i.e., 15.0 to $20.0 \mathrm{~mm}$ ) may have a better appetite after farrowing than sows with a thicker backfat. In addition, intravenous supportive treatment of postpartum sows with amino acid compound might also help to improve the appetite of postpartum sows and subsequently minimize backfat loss during lactation.

It is known that postpartum illnesses and/or low appetite in sows led to a number of postparturient disorders especially PDS or MMA. These abnormalities usually began within the first $24 \mathrm{~h}$ after farrowing as can be exemplified by several clinical symptoms, e.g., high fever, reduced appetite and the presence of abnormal vaginal discharge. It has been demonstrated that bacteria causing postparturient disorders mainly include Escherichia coli, Staphylococci and Streptococci (Kemper and Gerjets, 2009; Gerjets and Kemper, 2009). However, no significant difference in the isolated bacteria between healthy and diseased sows has been noted. This indicated that the development of clinical postparturient disorders and actual infection seemed to be largely dependent on individual resistance of individual sows (Kemper and Gerjets, 2009). Although antibiotics seemed to be the most important treatment in postpartum sows, additional supportive treatment should also be considered. In the present study, both groups used the same antibiotics and antiinflammatory drugs. Hence, sows with and without the supplement of intravenous amino acid compound were compared. However, it should be noted that the supplement contained not only amino acids (e.g., tryptophan, arginine, $L$-cysteine, phenylalanine, lysine, etc.), but also vitamins (e.g., B12, B2, B1 and nicotinamide) and minerals (e.g., calcium, magnesium, potassium, etc.). These components are also important for postpartum sows. The present study demonstrated that the intravenous supportive treatment of postpartum sows with amino acids and vitamin compounds could positively enhance the healthiness of the sows as illustrated by a lower proportion of sows with reduced appetite during the first few days postpartum.

In conclusion, the backfat thickness of sows at farrowing influenced backfat loss during lactation under hot and humid climates. The intravenous supportive treatment of sows with amino acid compound improved the appetite of postpartum sows.

\section{REFERENCES}

Einarsson, S. and T. Rojkittikhun. 1993. Effect of nutrition on pregnant and lactating sows. J. Reprod. Fertil. Suppl. 48:229239.

Gerjets, I. and N. Kemper. 2009. Coliform mastitis in sows: A Review. J. Swine Health Prod. 17:97-105.

Glock, X. T. P. and G. Bilkei. 2005. The effect of postparturient urogenital diseases on the lifetime reproductive performance of sows. Can. Vet. J. 46:1103-1107.

Kemper, N. and I. Gerjets. 2009. Bacteria in milk from anterior and posterior mammary glands in sows affected and unaffected by postpartum dysgalactia syndrome (PPDS). Acta Vet. Scand. 51:26.

Klopfenstein, C., C. Farmer and G. P. Martineau. 2006. Diseases of the mammary glands, In: Diseases of Swine (Ed. B. E. Straw, J. J. Zimmerman, S. D'Allaire and D. J. Taylor), $9^{\text {th }}$ Edition. Blackwell Publishing, pp. 57-74.

Love, R. J., G. Evans and C. Klupiec. 1993. Seasonal effects on fertility in gilts and sows. J. Reprod. Fertil. Suppl. 48:191-206.

Marchant, J. N., A. R. Rudd, M. T. Mendl, D. M. Broom, M. J. Meredith, S. Corning and P. H. Simms. 2000. Timing and causes of piglet mortality in alternative and conventional farrowing systems. Vet. Rec. 147:209-214

Markowska-Daniel, I. and M. Pomorska-Mol. 2010. Shifts in immunoglobulins levels in the porcine mammary secretions during whole lactation period. Bull Vet. Inst. Pulawy 54:345349 .

Milligan, B. N., C. E. Dewey and A. F. De Grau. 2002. Neonatalpiglet weight variation and its relation to pre-weaning mortality and weight gain on commercial farms. Prev. Vet. Med. 56:119-127.

Papadopoulos, G. A., C. Vanderhaeghe, G. P. J. Janssens, J. Dewulf and D. G. D. Maes. 2010. Risk factors associated with postpartum dysgalactia syndrome in sows. Vet. J. 184:167-171.

Peltoniemi, O. A. T., R. J. Love, M. Heinonen, V. Tuovinen and H. Saloniemi. 1999. Seasonal and management effects on fertility of the sow: a descriptive study. Anim. Reprod. Sci. 55:47-61.

Suriyasomboon, A., N. Lundeheim, A. Kunavongkrit and S. Einarsson. 2006. Effect of temperature and humidity on reproductive performance of crossbred sows in Thailand. Theriogenology 65:606-628.

Tantasuparuk, W., A-M. Dalin, N. Lundeheim, A. Kunavongkrit and S. Einarsson. 2001. Body weight loss during lactation and its influence on weaning-to-service interval and ovulation rate in Landrace and Yorkshire sows in the tropical environment of Thailand. Anim. Reprod. Sci. 65:273-281.

Tummaruk, P, W. Tantasuparuk, M. Techakumphu and A. Kunavongkrit. 2010. Seasonal influence on the litter size at birth of pig are more pronounced in the gilt than sow litter. J. Agri. Sci. 148:421-432.

Tummaruk, P. 2010. Effect of backfat loss during lactation on weaning-to-oestrus interval in sows. Proc. $9^{\text {th }} \mathrm{CU}$. Vet. Sci. Ann. Con., Bangkok, Thailand, p. 96.

Tummaruk, P., N. Lundeheim, S. Einarsson and A-M. Dalin. 2000. Reproductive performance of purebred Swedish Landrace and Swedish Yorkshire sows: I. Seasonal variation and parity 
influence. Acta Agric. Scand., Sect. A -Anim. Sci. 50:205-216. Tummaruk, P., W. Tantasuparuk, M. Techakumphu and A. Kunavongkrit. 2004. Effect of season and outdoor climate on litter size at birth in purebred Landrace and Yorkshire sows in Thailand. J. Vet. Med. Sci. 66:477-482.
Tummaruk, P., W. Tantasuparuk, M. Techakumphu and A. Kunavongkrit. 2007. Age, body weight and backfat thickness at first observed oestrus in crossbred Labdrace $\times$ Yorkshire gilts, seasonal variations and their influence on their subsequent reproductive performance. Anim. Reprod. Sci. 99:167-181. 